\title{
Moroccan Version of the Mattis Dementia Rating Scale: The Effects of Age, Education, and Gender
}

\author{
Siham Sanhaji ${ }^{1,2 *}$, Imane Elargoub1,2, Chloe Lemaréchal1,2, Maria Benabdeljlil1,2, \\ Mostapha El Alaoui Faris ${ }^{1,2}$
}

Faculty of Medicine and Pharmacy, University Mohammed V, Rabat, Morocco

Department of Neurology and Neuropsychology A, Specialty Hospital, Rabat, Morocco

Email: *sanhajineuropsy@gmail.com

How to cite this paper: Sanhaji, S., Elargoub, I., Lemaréchal, C., Benabdeljlil, M. and El Alaoui Faris, M. (2018) Moroccan Version of the Mattis Dementia Rating Scale: The Effects of Age, Education, and Gender. World Journal of Neuroscience, $\mathbf{8}$, 90-97.

https://doi.org/10.4236/wjns.2018.81008

Received: December 24, 2017

Accepted: January 29, 2018

Published: February 1, 2018

Copyright $\odot 2018$ by authors and Scientific Research Publishing Inc. This work is licensed under the Creative Commons Attribution International License (CC BY 4.0).

http://creativecommons.org/licenses/by/4.0/

\begin{abstract}
The present study aims to adapt and to standardize the MDRS in the Moroccan population. The Moroccan Dementia Rating Scale was adapted in Arabic and was administered to 192 younger and older individuals without cognitive deficits (96 men and 96 women) whose ages ranged from 18 to 85 years old. To investigate the impact of age and schooling, participants were classified into three levels of education, and three age categories. The results show that age and level of education strongly influenced the performance of an average of 124/144 of the MDRS subjects who were tested.
\end{abstract}

\section{Keywords}

MDRS, Morrocan Population, Age, Education

\section{Introduction}

The Dementia Rating Scale "RS" was developed by Coblentz et al. in 1973 and was taken over in 1976. The name was changed to Mattis Dementia Rating Scale (MDRS) in 1988.

The "MDRS" is correlated with conventional intelligence tests, with conventional intelligence tests. So, it is considered by many researchers to be a tool for research and clinical practice at the same time. Easy to apply and brief to administer, the process lasts between 30 to 40 minutes for patients with dementia. It includes 36 tasks which are grouped into five subscales. Each task aims to assess different cognitive functions which are: attention, initiation, perseveration, construction, conceptualization, and Memory. 
Due to the increasing number of studies that have been undertaken, the value of the MDRS in the diagnosis and in the research of any differentiation between $\mathrm{AD}$ (Alzheimer's Disease) patients and those patients with other neurodegenerative diseases (such as Parkinson's disease, Core Huntington, and vascular dementia) has been confirmed. A Hungarian study, the aim of which was to evaluate the sensitivity and specificity of different neuropsychological tests (Addenbrooke's Cognitive Examination, ACE; Frontal Assessment Battery, FAB and Mattis Dementia Rating Scale, MDRS) in Parkinson's disease patients, showed that the MDRS had "the best clinicometric profile for detecting PDD" [1].

However, the MDRS is not the appropriate test to detect MCI since it generates numerous misclassified cases [2].

The MDRS has been translated into different languages, and adapted in different countries. So, we have adopted the same procedure for our population. The test was adapted in Arabic and standardized thereafter in Morocco.

\section{Method}

\subsection{Equipment}

We translated and adapted the MDRS into colloquial Arabic. It was later applied to healthy subjects individually, in the order prescribed by its Author (Mattis).

The Moroccan version of the MDRS contains 5 subtests, to which we made the following modifications:

In the subtest "Attention", the letter " $\mathrm{A}$ " of the item 30 and 31 has been replaced by the Arabic letter \{\} ; the other Latin letters have also been replaced with Arabic letters. And, in the item 34 of "Word reading", all the words have been translated into Arabic. The figures were moved to the right in the items "construction" and "initiation". In items 23, 25 and 26 belonging to the subtest "conceptualization", similarities have been translated into Arabic as well as the two words of the sub-scale "construction" of the sentence in item 28 in the subtest "memory", the subject is brought to name the King instead of the President, and the wife of the King instead of the Mayor in the item 29. And in the item 32 the sentence to remember was also translated and adapted, as well as the words of the verbal recognition of the item 35 . We kept the same rating for the total score or for the sub-scales.

\subsection{Participants}

This study focuses on a sample of 192 Moroccan participants (96 men and 96 women), classified into four age groups ( 18 - 39 years, 40 - 59 years, 60 - 69 years and $\geq 70$ years) and three educational levels ( $3-6$ years, 7 - 10 years and $\geq 11$ years). Participants are at least 18 years old, of Moroccan nationality, and have at least three years of education. However, we excluded anyone with disorders including hearing, visual (or engines), (history of) psychiatric, neurological, depression, substance abuse, hypertension (HTA), or diabetes. All participants were selectedat home, companies, factories, stations, and associations. 


\section{Results}

We identified an average total score of $124\{ \pm 4.64\}$ subjects with an average of 8.64 years of schooling. We obtained the following averages in the subtests: 35 in the subtest Attention, 29.8 in the subtest Initiation, 35.9 in the subtest Construction, 30.6 in the Conceptualization and 23.4 in Memory.

\subsection{Effect of the Educational Level}

Less educated and older subjects scores are lower than those scores of younger subjects and of subjects with higher levels education (Table 1).

The most affected subtests by the level of education are: "Initiation" and "conceptualization". We note on occasion the difference between the two groups

Table 1. Moroccan norms by age and level of education (means were calculated by excel).

\begin{tabular}{|c|c|c|c|c|c|c|c|c|}
\hline \multirow{2}{*}{$\begin{array}{c}\text { Age groups } \\
\text { Education } \\
\text { level (by years } \\
\text { of schooling) }\end{array}$} & \multicolumn{2}{|c|}{18 to 39 years } & \multicolumn{2}{|c|}{40 to 59 years } & \multicolumn{2}{|c|}{60 to 69 years } & \multicolumn{2}{|c|}{$\geq 70$ years } \\
\hline & $\begin{array}{l}\text { Mean of } \\
\text { subtests }\end{array}$ & $\begin{array}{c}\text { Mean of } \\
\text { total } \\
\text { score }\end{array}$ & $\begin{array}{l}\text { Mean of } \\
\text { subtests }\end{array}$ & $\begin{array}{c}\text { Mean of } \\
\text { total } \\
\text { score }\end{array}$ & $\begin{array}{l}\text { Mean of } \\
\text { subtests }\end{array}$ & $\begin{array}{c}\text { Mean of } \\
\text { total } \\
\text { score }\end{array}$ & $\begin{array}{l}\text { Mean of } \\
\text { subtests }\end{array}$ & $\begin{array}{c}\text { Mean of } \\
\text { total } \\
\text { score }\end{array}$ \\
\hline \multirow{8}{*}{3 to 6 years } & Attention: & \multirow{8}{*}{119.37} & Attention: & \multirow{8}{*}{121.12} & Attention: & & Attention: & \multirow{8}{*}{115.31} \\
\hline & Initiation: & & Initiation: & & Initiation: & & Initiation: & \\
\hline & 28.12 & & 28.25 & & 26.62 & & 26.75 & \\
\hline & Construct: & & Construct: & & Construct: & 119.81 & Construct & \\
\hline & 5.93 & & 6 & & 5.93 & & 5.43 & \\
\hline & Concept: & & Concept: & & Concept: & & Concept: & \\
\hline & 27.93 & & 28.56 & & 28.81 & & 28.25 & \\
\hline & 23.81 & & 23.62 & & 23.75 & & 21.25 & \\
\hline \multirow{10}{*}{7 to 10 years } & Attention: & & Attention: & \multirow{10}{*}{126.18} & Attention: & & Attention: & \multirow{10}{*}{121.69} \\
\hline & 35.87 & & 35.37 & & 34.62 & & 35.06 & \\
\hline & Initiation: & & Initiation: & & Initiation: & & Initiation: & \\
\hline & 29.81 & & 30.12 & & 29.75 & & 27.5 & \\
\hline & Construct: & 12506 & Construct: & & Consruct: & 12431 & Construct & \\
\hline & 6 & 123.00 & 6 & & 6 & 124.01 & 5.87 & \\
\hline & Concept: & & Concept: & & Concept: & & Concept: & \\
\hline & 29.37 & & 30.87 & & 30.31 & & 30.5 & \\
\hline & Memory: & & Memory: & & Memory: & & Memory: & \\
\hline & 24 & & 23.81 & & 23.62 & & 22.75 & \\
\hline \multirow{9}{*}{$\geq 11$ ans years } & 36.18 & & 36.06 & \multirow{9}{*}{132.37} & 35.18 & & 34.5 & \multirow{9}{*}{125.81} \\
\hline & Initiation: & & Initiation: & & Initiation: & & Initiation: & \\
\hline & 33.68 & & 33.06 & & 31.43 & & 29.56 & \\
\hline & Construct: & 134.43 & Construct: & & Construct & 128.56 & Construct & \\
\hline & 6 & & 6 & & 6 & & 5.93 & \\
\hline & Concept: & & Concept: & & Concept: & & Concept: & \\
\hline & 34.62 & & 33 & & 32.06 & & 31.81 & \\
\hline & Memory: & & Memory: & & Memory: & & Memory: & \\
\hline & 23.93 & & 24.25 & & 24.25 & & 24 & \\
\hline
\end{tabular}


of educational levels: 3 to 6 years, and 11-year and more of schooling. Furthermore there is little significant difference between the levels of $3-6$ years and 7 10 years of schooling. Also, subjects with 3 - 6 years of schooling received an average total score of 119.32. And those of 7 - 10 years got an average of 124.31. While participants having a level of education of 11 years and over, received a total score of 130.29 .

The most affected sub-scales by the level of education are subtests "initiation" and "conceptualization". So subjects with educational level of 3 to 6 years scored an average of 28/37 in the subtest "Initiation", and an average of 28/39 in the subtest "conceptualization". While; participants in level of education from 11 years and over had an average scores of $31 / 37$ in the sub-scale "Initiation" and an average of 32/39 in the subtest "conceptualization".

\subsection{Effect of Age}

The young subjects exhibit higher scores than the older subjects. Those aged 18 to $39 \mathrm{had}$ an average total score of $126 / 144$ while the older participants of $\{70$ years and more had an average of 122/144. Therefore, the effect of age on scores is remarkable in terms of total scores as the level of subtests. This result means that performance at the MDRS decreases with advancing in age.

\subsection{Effect of Gender}

No influence of sex has been demonstrated in our participants. Both men and women groups had an average score of 124/144.

\section{Discussion}

We obtained an average total score of $124.64\{ \pm 4.32\}$, in subjects whose average years of schooling is 8.64 . The main results show the influence of demographic variables on the performance of subjects to Mattis. From a descriptive point of view, we found that the more educated people get higher scores; Thus the most important difference appears between the performance of participants with low levels of education ( 3 - 6 years), and subjects with a high level (7 to 10 years, 11 years or more).

The total score is often influenced by the level of education: The higher the level of education, the higher the score. This was also demonstrated in the study of Markopoulos et al. [3], in which the average age of African American subjects and subjects of European origins was 76.5. Then Chey et al. [4] conducted a study of standardisation in the Korean population. Also, Letenneur et al. [5] demonstrated the impact of education on the performance of the tests short-term memory and long-term declarative memory. This is confirmed by a Senegalese Cohort with Kamadore et al. [6] which shows that the prevalence of dementia varies with the level of education.

Our participants with less than 6 years of education had an average total score of 118.3, while those with more than 6 years of schooling had an average of 
130.3. For its part, Brazil, Porto [7], confirmed the effect of education on the total score. Indeed, participants with educational level between 4 and 8 years achieved an overall average of 127.2, and those with 11 years of schooling had 131.86. While the most educated with 15 years of education had an average total score of 137.5. This influence was also found at the subtests, mainly the "Introduction" and "Conceptualization" where the subjects lose more marks. And the difference is more apparent among participants with education level 3 to 6 and 11 years and those with more education.

Age also has an impact on performance issues, since young subjects had higher scores than older subjects. Fact reported in a French study with Disarranges et al. [8] involving 60 healthy subjects, aged 56 to 93, divided into three age groups, shows that age has a significant effect on performance, highlighted by tests of explicit memory, by Launer et al. [9]. These results are not supported by Foss et al. [10] and Scot et al. [11], since they have not found the influence of age on the performance of participants.

Unlike age and level of education, "sex" could not be identified to impact the scores of the Mattis. Observations also cited by Haugarvoll et al. [12]. By Cons, Chan et al. [13] demonstrated the influence of "gender" on performance at the MDRS, male and female participants from Hong Kong, differed in terms of total scores and subscale level, particularly subtest of attention, where the average for men was 36.05 (1.68), while that for women was 34.81 (4.76). The average total score recorded among men was 133.23 (8.63) against 129.20 (12.70) in women. But these women were generally of a lower level of education, and a more advanced age;

A U. S. study by Adam et al. [14] on the elderly (61 to 94 years) living in rural areas shows that the performance of women in the MDRS is higher than those of men; This fact has not been reported by Brian et al. [15], Lucas et al. [16], Monsch et al. [17] and Smith [18] because they did not include records of gender on performance; Also, no influence of male and female was found to be included in our Moroccan results; since the two groups of both sexes had an average total score of 124/144. Our results are consistent adaptation studies discussed in the theoretical part of this study, where the effect of demographic variables on the performance of the MDRS is also described; Descriptive data were analyzed, with the effects of demographic factors on the M-DRS scores analyzed with the initial sample of 192 participants. Spearman's analysis yielded no significant educational $(p=1)$ or age $(p=1)$ effects.

Various standardized studies of this test are based solely on elderly, unlike our sample, which includes different age groups (elderly and young subjects). So we are contented with elderly participants in our comparison with these studies, for example Korean participants [4] obtained approximately the same average as our participants. The Korean subjects aged 65 - 84 and having over than six years of schooling, had an average total score of 127.8 and our participants having the same level of education had an average total score of 125.9. Otherwise, 
Chinese [19], Brazilian [7] and Argentinian [20] scores, appear to be superior to the performance of our participants having the same age and level of education;

Our results are consistent adaptation studies in the theoretical part of this study where the effect of demographic variables on the performance of the MDRS, is also described as well. In recent years, studies have indicated that cross-sectional normative samples of older adults in Mayo's Older Americans Normative Studies (MOANS) represent an admixture of participants who are cognitively normal and participants who have developing neurodegenerative disease, which can theoretically lead to a reduction in the clinical utility of the norms [21]. This cognitive tool was also administered in the illiterate population in Brazil. These results showed that illiterate people performed significantly lower than their literate counterparts [22].

The normalisation of the MDRS in Morocco, thanks to its adaptation, will permit the use of a new neuropsychological tool which accounts for the different demographic variables for our population that are essentially the age and the level of education. Moreover, the validation of this scale in the parkisonian patients or Alzheimer's patients will be the issue of a future study.

\section{Conclusions}

The Mattis dementia rating scale was adapted in Arabic and administered individually to 192 healthy (not ill) persons between 18 and 85 years old, and with different education levels.

Descriptive data were analyzed with the effects of demographic factors on the M-DRS scores. Analysis yielded no significant educational $(p=1)$ or age $(p=1)$ effects. However, from a descriptive point of view, we found that the most educated and the youngest people had better scores. We obtained an average total score of $124.64\{ \pm 4.32\}$ in our population. These normative data will help avoid overdiagnosis and improve the accuracy of the diagnosis of dementia in Morocco.

\section{References}

[1] Kaszas, B., Kovacs, N., Balas, I., Kallai, J., Aschermann, Z., Zerekes, Z., Komoly, S., Nagy, F., Janszky, J., Lucza, T. and Karadi, L. (2012) Sensitivity and Specificity of Addenbrooke's Cognitive Examination, Mattis Dementia Rating Scale, Frontal Assessment Battery and Mini Mental State Examination for Diagnosing Dementia in Parkinson's Disease. Parkinsonism \& Related Disorders, 18, 553-556. https://doi.org/10.1016/j.parkreldis.2012.02.010

[2] Belaus, A., Fernández, L.A., Farías-Sarquis, Y., Adrián, M. and Bueno, M. (2015) Is the Mattis Dementia Rating Scale Appropriate to Detect Mild Cognitive Impairment? Revista Chilena de Neuropsicologia, 10, 8-13.

[3] Marcopulos, B.A., Mclain, C.A. and Giuliano, A.J. (1997) Cognitive Impairment or Inadequate norms? A Study of Health, Rural, Older Adults with Limited Education. The Clinical Neuropsychologist, 11, 111-131. https://doi.org/10.1080/13854049708407040

[4] Chey, J., Na, D.-R. and Park, S. (1998) Effects of Education in Dementia Assess- 
ment: Evidence from Standardizing the Korean-Dementia Rating Scale. The Clinical Neuropsychologist, 13, 294-298.

[5] Letenneur, L., Gilleron, V. and Commenges, D. (1999) Are Sex and Educational Level Independent Predictors of Dementia and Alzheimer's Disease? Incidence Data from the PAQUID Project. Journal of Neurology, Neurosurgery \& Psychiatry, 66, 177-183. https://doi.org/10.1136/jnnp.66.2.177

[6] Kmadore, T., Coumé, M. and Diale, N.N. (2008) Prevalence of Dementia in a Senegalese Elderly Population. African Journal of Neurological Sciences, 27.

[7] Porto, C.L., Fichman, H.C. and Caramelli, P. (2003) Brazilian Version of the Mattis Dementia Rating Scale Diagnosis of Mild Dementia in Alzheimer's Disease. Arquivos de Neuro-Psiquiatria, 61, 339-345. https://doi.org/10.1590/S0004-282X2003000300004

[8] Desgranges, B., Eustache, F. and Rioux, P. (1994) Effets de l'âge et du niveau d'étude sur différents sous-systèmes mnésiques. L'année Psychologique, 94, 345-367. https://doi.org/10.3406/psy.1994.28768

[9] Launer, L.J., Andersen, K. and Dewey, M.E. (2007) Rates and Risk Factors for Dementia and Alzheimer's Disease-Results from EURODEM Pooled Analyses. American Academy of Neurology.

[10] Foss, M.P., De Assis Carvalho do Vale, F. and Speciali, J.G. (2005) Influencia da escolaridade na avaliaçao Neuropsicologica de idosos. Arquivos de Neuro-Psiquiatria, 63, 119-126.

[11] Scot, A.L., Hernandez, I., Chui, E.C. and Teng, E.L. (2006) Performance of Spanish Speakers on the Mattis Dementia Rating Scale. Archives of Clinical Neuropsychology, 21, 827-836. https://doi.org/10.1016/j.acn.2006.09.003

[12] Haugarvoll, K., Aarsland, D. and Wentzel-Larsen, T. (2005) The Influence of Cerebrovascular Risk Factors on Incident Dementia in Patients with Parkinson's Disease. Acta Neurologica Scandinavica, 112, 386-390.

[13] Chan, A.S., Choi, M.-K. and Salmon, D.P. (2001) The Effects of Age, Education, and Gender on the Mattis Dementia Rating Scale Performance of Elderly Chinese and American Individuals. Pyschological Sciences, 56, 356-359.

https://doi.org/10.1093/geronb/56.6.P356

[14] Bank, A.L., Yochim, B.P. and MacNeill, S.E. (2000) Expanded Normative Data for the Mattis Dementia Rating Scale for Use with Urban, Elderly Medical Patients. The Clinical Neuropsychologist, 14, 145-156.

[15] Yochim, B.P., Bank, A.L., Mast, B.T., MacNeill, S.E. and Lichtenberg, P.A. (2003) Clinical Utility of the Mattis Dementia Rating Scale in Older, Urban Medical Patients: An Expanded Study. Aging Neuropsychology and Cognition, 10, 230-237.

[16] Lucas, J.A., Ivnik, R.J. and Smith, G.E. (1998) Normative Data for the Mattis Dementia Rating Scale. Journal of Clinical and Experimental Neuropsychology, 20, 536-547. https://doi.org/10.1076/jcen.20.4.536.1469

[17] Monsch, A.U., Bondi, M.W. and Salmon, D.P. (1995) Clinical Validity of the Mattis Dementia Rating Scale in Detecting Dementia of the Alzheimer Type. Archives of Neurology, 52, 899-904. https://doi.org/10.1001/archneur.1995.00540330081018

[18] Smith, G.E., Ivnik, R.J. and Malec, J.F. (1994) Psychometric Properties of the Mattis Dementia Rating Scale. Assessment, 1, 123-131. https://doi.org/10.1177/1073191194001002002

[19] Chan, A.S., Choi, A. and Chiu, H. (2003) Clinical Validity of the Chinese Version of Mattis Dementia Rating Scale in Differentiating Dementia of Alzheimer's Type in 
Hong Kong. Journal of the International Neuropsychological Society, 9, 45-53. https://doi.org/10.1017/S1355617703910058

[20] Luis Fernandez, A. and Scheffel, D.L. (2003) Study of the Criterion Validity of the Mattis Dementia Rating Scale. International Journal of Testing, 3, 49-58. https://doi.org/10.1207/S15327574IJT0301_3

[21] Pedraza, O., Lucas, J.A., Smith, G.L., Petersen, R.C., Graff-Radford, N.R. and Ivnik, R.J. (2010) Robust and Expanded Norms for the Dementia Rating Scale. Archives of Clinical Neuropsychology, 25, 347-358. https://doi.org/10.1093/arclin/acq030

[22] Foss, M.P., Amaral de Carvalho, V., Machado, T.H., Cássio dos Reis, G., Tumas, V., Caramelli, P., Nitrini, R. and Porto, C.S. (2013) Mattis Dementia Rating Scale (DRS) Normative Data for the Brazilian Middle-Age and Elderly Populations. Dementia \& Neuropsychologia, 7, 374-379.

https://doi.org/10.1590/S1980-57642013DN74000004 